\title{
Student Perception Of Traditional Versus Alternative Textbook Value
}

\author{
Ann Kuzma, Minnesota State University, Mankato, USA \\ John Kuzma, Minnesota State University, Mankato, USA \\ Harold Thiewes, Minnesota State University, Mankato, USA
}

\begin{abstract}
In today's environment of rising tuition and textbook costs, we surveyed business majors concerning their preferences regarding various text options that are available for their academic studies. Specifically, we surveyed 329 students enrolled in upper-level business courses at a midlevel Association to Advance Collegiate Schools of Business (AACSB) accredited Midwestern university. Students were asked to report the variety of classroom texts that they have utilized in the past and their text preferences based on their text experiences From the sample of students, $67 \%$ reported that they had used an online e-text for one or more of their classes. However, only 41 of the 220 students, or 19\%, believed that the online e-text was a better learning vehicle or more convenient than the traditional text they used in their other classes. The entire sample of 329 students was also asked if they had a preference for a course text mode based on whether the course was a part of their major, involved extensive reading, analytical work, or was terminology oriented. In all areas, the students indicated a slight or strong preference for the traditional hard text.
\end{abstract}

Keywords: Online Textbooks and Materials; E-Textbooks; E-Books; Traditional Textbooks and Materials

\section{INTRODUCTION}

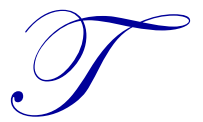

oday's technological environment has influenced and transformed not only the educational environment, but also the technological backgrounds of students while significantly impacting the options provided by the publishing industry. College instructors have never had more options from which to select in terms of learning tools. No longer are students lining up at bookstores at the beginning of each semester to purchase the required textbooks for their classes, hoping that a few used books will be left on the shelves. Many students purchase, or even rent, their textbooks online, either from the college bookstore, or through other vendors who may offer more competitive prices. A dramatic change, however, has been the change from socalled traditional textbooks to online versions of those textbooks, or possibly e-books.

\section{LITERATURE REVIEW}

A 2011 study by the American Enterprise Institute reported that college textbook prices have risen $812 \%$ since 1978, exceeding the 559\% increase in tuition and fees over the same 30-year period (Kingkade, 2013). According to the U.S. Department of Labor, textbook prices rose 8.1\% from July 2011 to July 2012, while prices for all goods only grew by $1.4 \%$ overall (Kurtzleben, 2012). The National Association of College Stores (NACS) estimated that the average college student spends $\$ 655$ each year on textbooks (Kingkade, 2013). The College Board, however, put the cost much higher, at $\$ 1,168$, with students at for-profit colleges spending even more (Kingkade, 2013). A representative from Student Monitor, a market research firm, estimated that the average annual spending per student was around $\$ 598$ in 2011, down from $\$ 677$ in 2008 (Kurtzleben, 2012). The firm acknowledged that the decline was not due to textbook costs going down, but rather that students no longer buy them. A survey conducted by Student Monitor reported that more than $40 \%$ of students attending 4-year colleges do not buy all of the required books for their classes, primarily because they cannot afford them (Kurtzleben, 2012). 
These rising textbook costs, along with higher tuition, have no doubt contributed to the debt that more and more students have amassed. The Institute for College Access \& Success (2011) reported that the average student debt load of the $66 \%$ of college seniors who graduated with student debt in 2011 was $\$ 26,000$, with state averages ranging from $\$ 17,250$ to $\$ 32,450$. While the percentage of college expenses that is attributed to textbook costs will vary from student to student, major to major, and institution to institution, clearly it accounts for a significant portion. Students are further frustrated when professors do not fully use the so-called required texts, or, worse yet, do not use them at all. New editions of existing textbooks, which are released on average every 3.9 years, also drive up prices (Kingkade, 2013).

Another issue that has impacted the educational environment pertains to the behavior of students when it comes to their usage of textbooks. A widely reported 2011 study found that $35 \%$ of the students sampled spent 5 hours or less a week studying alone; the average for all students was under 9 hours (Vedder, 2011). Another 2011 study that focused specifically on business majors reported that seniors majoring in business spent, on average, less than 11 hours a week studying outside of class, and much of that time was spent studying in groups (Glenn, 2011). This flies against the well-established rule of thumb that students should devote at least 2 hours of study time for every hour of class time. Thus, a full-time undergraduate student who is registered for 15 credit hours, for example, should be studying approximately 30 hours per week. This study further reported that $32 \%$ of students do not even take courses that require more than 40 pages of reading a week and that many students failed to demonstrate any improvement in critical thinking skills after 4 years of university study (Jaschik, 2011). In contrast, a March 2012 study by the Pew Research Center found that $84 \%$ of college graduates say that the expense of going to college was a good investment for them.

Although a great many factors contribute to the overall collegiate experience for students, the learning environment, in particular the classroom, is clearly one of the most important. The current tough economy has forced many professors to accept increases in class size and course loads, which often leads them to cut down on student assignments. Another factor that has significantly impacted the college learning environment is technology. In addition to the so-called traditional textbooks that can be obtained, new or used, at the bookstore or from online vendors, students may choose to buy or rent e-textbooks on their Kindles, Nooks, iPads, or other tablets. Many publishers offer their textbooks in downloadable form for purchase by students to view on their laptop or desktop computers. In addition to the textbooks, publishers have developed online study tools that include PowerPoint slides, interactive games, quizzes, and videos to accompany the texts. College students are well-equipped to take advantage of these electronic pedagogical tools. A Pew Research Center study estimated that approximately $88 \%$ of undergraduate students own a laptop computer, with $84 \%$ owning an iPod or other mp3 player and nearly $100 \%$ having access to the Internet (Smith, Rainie, \& Zickuhr, 2011). A Pew Research Center study that surveyed college presidents found that more than $77 \%$ of respondents said their institution offered online course offerings with half speculating that most students at their schools will be enrolled in at least some online classes within the next 10 years (Anderson, Boyles, \& Rainie, 2012).

What college students face today is a complex environment in which courses, textbooks, and overall learning are constantly being modified and restructured in an effort to stay abreast of current technology and the needs of the marketplace. A review of the literature revealed a progression of research that initially examined ebook usage based on the technological aspects of various devices, often by reporting the results of e-reader pilot programs (Foster \& Remy, 2009; Rickman, Von Holzen, Klute \& Tobin, 2009; Trustees of Princeton University, 2010). Recent research has examined usage within subject areas and how the use of e-books could impact the classroom learning environment. Fernandez (2003) compared the use of e-books and print books at the University of North Carolina. For the 2-year period from 2001 to 2002, the study found that print titles were used more than their electronic versions. Breaking it down by subject area, however, was more revealing of usage patterns and preferences. Computer science, business, economics, management, and religion had a clear preference for e-books; medicine and psychology showed even usage; and social sciences, history, arts, education, and literature showed a preference for print (Fernandez, 2003). This particular study, however, only examined library circulation of e-books and print titles, not undergraduate textbook purchases. Furthermore, it should be noted that this study is now more than 10 years old, and thus does not reflect any impact the recent surge in the use of tablets has had on the use of ebooks. A 4-year study conducted at the College of Mount St. Joseph concluded that students had mixed feelings about using e-books. Students would use e-books, but preferred traditional print versions (Gregory, 2008). Again, 
this study focused on general preferences and library usage rather than required course textbooks. Falling in between the area of e-books and print titles in terms of academic resource tools are the so-called ancillaries that accompany both, and have become increasingly available in online versions directly through a publisher's website. In a study of the student use of online tools, Austin, Biss, and Wright (2010) concluded that students viewed such tools as helpful, regardless of whether or not they actually used them. Specifically, only $46 \%$ of students accessed any of the available aids. Our study proposes to examine upper-level business student preferences regarding the textbook mode they would prefer to use in their academic studies.

\section{THE STUDY}

In this environment of rising costs and reduced student textbook reading, we surveyed 329 students enrolled in upper-level business courses at a mid-level AACSB accredited Midwestern university and examined their preferences for the traditional hard copy textbook as opposed to alternative forms of text delivery. Specifically, we asked students to report their experience with the traditional hard copy versus the e-text and their current text preferences. Two hundred twenty students, or $67 \%$ of the sample, reported that they had used an online e-text for one or more of their classes. Of those students who had used an e-text, only 41 of the 220 students, or $19 \%$, thought that the online e-text was a better learning vehicle or more convenient than the traditional hard copy text they used in their other classes. This group was also asked to rate, on a 1 (important) to 5 (unimportant) Likert scale, certain factors considered important in the student e-text experience. Results are presented in Table 1. Price was rated as the most important attribute, achieving an average rating of 1.44 , with $166(75 \%)$ of the students identifying price with the highest importance rating, 1 . The other factors were rated lower in terms of importance with the attributes convenience, ease of note-taking, and resale value receiving average ratings of $2.30,2.50$ and 2.60 respectively.

Table 1

Factor Importance in Students' E-text Experience

\begin{tabular}{lcc}
\hline Factor & Weighted Average & \# Rating the Factor the Highest in Importance (1) \\
\hline Price & 1.44 & 166 \\
Convenience & 2.30 & 61 \\
Ease of Note Taking & 2.50 & 60 \\
Resale Value & 2.60 & 54 \\
\hline
\end{tabular}

Note. Responses of 220 of students who had used e-text for class

Rating Scale of 1 (Important) to 5 (Unimportant)

We also believed that the time students spent reading the assigned texts would impact their decisions on the texts' value at the conclusion of the semester. Accordingly, we asked students to provide the amount of hours over an average week that they spent reading their textbooks for all of their courses. Of the 329 students, 81 (24\%) indicated they spent fewer than 5 hours per week reading the assigned texts and $243(74 \%)$ indicated that they spent fewer than 10 hours per week reading assigned text. In terms of the texts' value to the student, only 10 of the 329 students indicated that they keep all of their texts at the semester's conclusion, and slightly over half of the students, $171(52 \%)$, stated that they try to sell all of their textbooks at the semester's conclusion. However, $105(32 \%)$ indicated that they do keep texts if they are in their major area of study. Thus, it is not surprising that the low rate of text readership would result in many of the students wanting to sell their texts back at the end of the semester and overall price would be of utmost importance. However, of somewhat surprise is that resale was rated of lower importance, in contradiction to the price attribute. This may be due to the fact that the resale value of the text is unknown at the time of purchase. Results are provided in the Table 2.

These results are also confirmed by examining the relationship between the weekly hours spent on reading the text with the students' decision to keep or dispose of the text at the end of the semester. If a student would spend less than 5 hours per week reading the assigned text, 57 (70\%) of the 81 students in this group would like to sell all of their texts, but if they spent between 10 and 15 hours per week reading assigned text, only 26 (38\%) of the 68 students in this higher readership group would like to sell all of their texts. Also, only $11(14 \%)$ of the low readership group would keep texts in their major area of study, while $29(43 \%)$ of the 10 to 15 hour readership group would keep the texts in their major area of study. Results presented in Table 2, demonstrate a definite upward trend in keeping texts and a downward trend in selling texts at the semester's conclusion based on the amount of time that 
the students invested in reading the assigned text. A chi square test was conducted on the relationship between hours spent reading the text and the students' text decisions at the completion of the course. Due to the small sample sizes in the "Keep All of my Texts" option and the two higher readership categories, the test was conducted on the relationship between the lower three readership categories and the other three textbook decision categories. Thus, 303 of 329 student responses are involved in the tests. Results of the 3 × 3 matrix resulted in a $X^{2}=19.95$ (Critical $\left.X^{2}=14.82\right)$, significant at the .005 level. Inclusion of all of the data in Table 2 also resulted in significance at .005 .

Table 2

Student Textbook Decision Upon Class Completion based on Hours Reading Text

\begin{tabular}{|c|c|c|c|c|c|c|}
\hline $\begin{array}{c}\text { Time Reading Text Per Week } \\
\text { Text Decision }\end{array}$ & $\mathbf{X}<5$ & $5<X<10$ & $10<X<15$ & $15<X<25$ & $X>25$ & Total \\
\hline Keep All of My Texts & 3 & 3 & 3 & & 1 & 10 \\
\hline Keep Only Texts in Major & $11(14 \%)$ & $59(36 \%)$ & $29(43 \%)$ & 5 & 1 & 105 \\
\hline $\begin{array}{l}\text { Keep Only Texts in Courses } \\
\text { Interested In }\end{array}$ & $10(12 \%)$ & $21(13 \%)$ & $10(14 \%)$ & 2 & & 43 \\
\hline $\begin{array}{l}\text { Try to Sell All Texts at End } \\
\text { of Semester }\end{array}$ & $57(70 \%)$ & $81(50 \%)$ & $26(38 \%)$ & 6 & 1 & 171 \\
\hline Total & 81 & 164 & 68 & 13 & 3 & 319 \\
\hline
\end{tabular}

Students were then provided with five text options and were asked to rank the five alternatives in terms of the highest (1) to the lowest (5) text cost. A weighted average was calculated by multiplying the specific number, 1 through 5, by the percent of the sample that selected each text mode. A used text from the bookstore was perceived to be the highest cost with a weighted average score of 2.14. One hundred and twelve (34\%) students selected this as the most expensive text form. Students believed this option to be even more expensive than purchasing a new hard-copy text online and reselling at the semester's end. This option resulted in a weighted average of 2.69 , although 90 students $(27 \%)$ thought that an online purchase of a new text would be the most expensive alternative, but overall less expensive than buying a used textbook from the bookstore. Renting and purchasing a customized text received weighted average scores of 3.12 and 3.09, respectively. Students clearly believed the cheapest text mode was the online text, even though the option stated there would be no resale value. This option resulted in a rather high weighted average score of 3.85 .

Table 3

Student Perception of Various Text Options

\begin{tabular}{lcc}
\hline \multicolumn{1}{c}{ Option } & Weighted Average & \# Rating 1 \\
\hline Purchasing Unused Hard-Copy from Bookstore and Selling at Semester's End & 2.14 & 112 \\
Purchasing Used Hard-Copy Text On-line and Selling at Semester's End & 2.69 & 90 \\
Purchasing Instructor's Customized Text/Reselling & 3.09 & 52 \\
Renting Hard-Copy, if possible & 3.12 & 63 \\
Purchasing On-line Text on Web (No Resale) & 3.85 & 20 \\
\hline
\end{tabular}

Students were also asked other questions regarding their preferences. When asked which is the preferred text if all costs are equal, $227(69 \%)$ preferred the traditional text, 67 (20\%) preferred a customized text prepared by the instructor, but only $31(9 \%)$ preferred the online e-text. Further, students were in general disagreement with the statement that they found online texts to be more convenient than traditional. Thus, even though price is the most important factor in textbook selection, which would support online text usage, students indicated a strong preference for the traditional text in terms of ease of usage and convenience.

The entire sample of 329 students was also asked whether they had a preference of a course text mode if the course was in their major, involved extensive reading, analytical or terminology. In all areas, the student averages indicated a slight or strong preference for the traditional hard text. It is somewhat surprising that courses that involved extensive reading, such as a literature course, received the highest student preference in terms of traditional text usage over the e-text. Results are provided in Table 4. 
Table 4

Textbook Preference Based on Nature of Course

\begin{tabular}{lc}
\multicolumn{1}{c}{ Course Type } & Weighted Average \\
\hline Extensive Reading such as Literature & 1.59 \\
Extensive Analytical Work such as Math/Accounting & 1.70 \\
Course in Major & 1.85 \\
Extensive Amount of Terminology & 2.10 \\
Extensive In-class Note Taking & 2.28 \\
\hline
\end{tabular}

Rating Scale: Strongly Prefer Hard Copy (1) to Strongly Prefer E-text (5)

Lastly, we asked students to identify their major and GPA to determine if major and GPA influenced their preferences. Many students listed two majors. Specifically, there were 31 respondents who reported both Accounting and Finance as double majors and 36 students who designated Marketing, Management, and/or International Business as a double major. Accordingly, we formed two groups. Group 1 was the Accounting and Finance (A/F) majors and Group 2 was the Management, Marketing, and International Business (M/M/IB) majors. This resulted in two subsamples of $125 \mathrm{~A} / \mathrm{F}$ majors and $147 \mathrm{M} / \mathrm{M} / \mathrm{IB}$ majors. Fifty-seven students had listed other majors such as Economics, Construction Management, Music Management, and so on, and were eliminated from the following analysis. These two groups exhibited virtually identical GPAs of 3.25; the correlation coefficient between major and GPA was an insignificant .023. However, a comparison of the two groups' weekly textbook reading revealed that both groups had a weighted average score in the 5 to 10 hour category with the A/F majors averaging 2.256 (approximately $7 \frac{1}{2}$ hours per week reading the text) and the M/M/IB majors averaging 2.02 (approximately 5 hours per week reading the text). Although the difference in text reading between majors was statistically significant at the .05 level $(t=2.427)$, there is not a noticeable difference in the majors' influence in the students' desire to keep their texts as a reference. As evidence of further similarity, $51 \%$ of the A/F majors and $55 \%$ of the $\mathrm{M} / \mathrm{M} / \mathrm{IB}$ majors opted to sell all of their texts at the semesters' conclusion.

\section{CONCLUSION}

Our study surveyed junior- and senior-level students enrolled in business courses at a publicly-supported state university to determine their attitudes and experiences with various text mode options. Our study is in general agreement with the previously cited studies in that 80 of the 329 students, or $24 \%$, spent fewer than 5 hours per week reading the assigned textbook. Two hundred forty-three students, or $74 \%$, spent fewer than 10 hours per week reading assigned text and slightly over half, 171 students, stated they try to sell all of their textbooks at the end of the semester. Although there was no meaningful difference in these preferences based on the students' majors, a significant difference was noted when examining the relationship between the number of hours spent reading the text on a weekly basis and the decision to keep the text at the semester's conclusion. This was clearly evident in the students' weekly reading habits and the decision to keep texts in their major area of study. In terms of the rising cost of higher education, it is not surprising that the students ranked textbook price as the most important characteristic in the textbook delivery form, but, if all costs are the same, including resale, the traditional hardcopy text is the preferred mode of text delivery.

Although students have expressed some reservations in preferring e-texts to traditional texts for their classes, technology will continue to improve this delivery to students. One can only expect that publishers will continue to perfect the online delivery content as well as learning and self-testing tools. And, as primary and secondary schools continue to implement new technologies into their classrooms, newer students may become more tolerant of nontraditional textbooks and materials.

\section{AUTHOR INFORMATION}

Dr. Ann Kuzma received her Ph.D. in Marketing from Kent State University in 1989. She has taught at Minnesota State University, Mankato from 1989 until the present and currently serves as the Chairperson for the Department of Marketing and International Business. E-mail: ann.kuzma@mnsu.edu

Dr. John Kuzma received his Ph.D. in Marketing from Kent State University in 1990. He has taught at Minnesota State University, Mankato from 1989 until the present. E-mail: john.kuzma@ @mnsu.edu (Corresponding author) 
Dr. Harold Thiewes received his Ph.D. in Finance from the University of Iowa in 1990. He has taught at Minnesota State University, Mankato and the University of Iowa from 1980 until the present and has previously served as the Chairperson for the Department of Finance. E-mail: harold.thiewes@mnsu.edu

\section{REFERENCES}

1. Anderson, J. Q., Boyles, L. J., \& Rainie, L. (2012). The future impact of the internet on higher education, Retrieved from http://www.pewinternet.org/ /media/Files/Reports/2012/PIP_Future_of_Higher_Ed.pdf

2. Austin, T. L., Biss, J., \&Wright, C. (2010). Student use of online study tools in business communication courses. Journal of Strategic Innovation and Sustainability, 6(4), 46-54.

3. Fernandez, M. (2003). A usage comparison for print and electronic books at the University of North Carolina Chapel Hill. Master's thesis, University of North Carolina, Chapel Hill, NC. Retrieved from http://ils.unc.edu/MSpapers/2827.pdf

4. Foster, G., \& Remy, E. (2009). E-books for academe: A study from Gettysburg College. Research Bulletin Issue 21: EDUCAUSE Center for Applied Research, pp., 2-13.

5. Glenn, D. (2011, April 14). The default major: Skating through business school. New York Times. Retrieved from http://www.nytimes.com/2011/04/17/education/edlife/edl-17business-t.html

6. Gregory, C. L. (2008). 'But I want a real book': An investigation of undergraduates' usage and attitudes toward electronic books. Reference and User Services Quarterly, 47(3), 266-273.

7. Jaschik, S. (2011, January 18). Academically adrift. Inside Higher Ed. Retrieved from http://www.insidehighered.com/news/2011/01/18/study finds large numbers of college students don t learn_much

8. Kingkade, T. (2013, January 4). College textbook prices increasing faster than tuition and inflation. The Huffington Post.

9. Kurtzleben, D. (2012, August 28). How your textbook dollars are divvied up. US News and World Report.

10. Rickman, J. T., Von Holzen, R., Klute, P., \& Tobin, T. (2009, July 30). A campus-wide e-textbook initiative. EDUCAUSE Quarterly. Retrieved from http://www.educause.edu/ero/article/campus-wide-etextbook-initiative

11. Smith, A., Rainie, L., \& Zickuhr, K. (2011). College students and technology. Retrieved from http://www.pewinternet.org/Reports/2011/College-students-and-technology/Report.aspx

12. The Institute for College Access \& Success. Student debt and the class of 2011. Retrieved from http://projectonstudentdebt.org/files/pub/classof2011.pdf

13. Trustees of Princeton University. (2010). The e-reader pilot at Princeton. Retrieved from http://www.princeton.edu/ereaderpilot

14. Pew Research Center. (2012). The future impact of the internet on higher education. Retrieved from http://www.pewinternet.org/ /media/Files/Reports/2012/PIP_Future_of_Higher_Ed.pdf

15. Vedder, R. (2011, January 20). Academically adrift: A must-read. The Chronicle of Higher Education. Retrieved from http://chronicle.com/blogs/innovations/academically-adrift-a-must-read/28423 